\title{
Politeness in Making Requests and Responses in Computer-mediated Communication among Chinese College Students
}

\author{
Zhongrui Wang \\ Guangdong University of Science and Technology, Dongguan, China
}

\begin{abstract}
This study aims to explore the politeness strategies used in making requests and responses in computer-mediated communication (CMC) among Chinese college students and the applicability of discursive approach to such analysis. Following the steps of previous studies using discursive approach, some extracts of chat history on WeChat concerning requests and responses are selected and showed to the interlocutors. Then the interlocutors were asked to judge the conversations from the perspective of politeness. By analyzing the data, this study found that various strategies were used in order to achieve politeness in CMC, which can be associated with Brown and Levinson's theory of politeness. This study also found that discursive approach can be applied in analyzing politeness in CMC well though it differs from face-to-face communication in some ways.
\end{abstract}

Index Terms - politeness, request, CMC, discursive approach

\section{INTRODUCTION}

In the so-called "information era", communication seems to be facilitated by the internet. The popularization of the internet has changed the society so profoundly. The $21^{\text {st }}$ century has witnessed the remarkable rise of the internet. People's lifestyles have been shaped by the internet in various ways. With connections to the internet, people can enjoy more convenience in many aspects of life. Many kinds of activities can be done on the internet, such as communicating with friends, searching for needed information, reading news or novels, playing games, learning new things, shopping and entertaining, etc. Countless deals are made on the internet, but among all the activities mentioned here, communicating with people on the internet ranks the first, according to The $41^{\text {st }}$ China Statistical Report on Internet Development conducted by China Internet Network Information Center (CNNIC) in 2018.

Again, according to CNNIC's report, people aged from 20 to 29 are the largest group of internet users, which account for $30 \%$ of internet users of all age-groups. In terms of occupation, students are the majority, accounting for $25.4 \%$. Combining the two characteristics of age and occupation, it is not difficult to find that college students are one of the most active groups of internet users.

The internet bridges the distance among people and makes communication easier and faster. A growing number of people are now using various social media platforms to connect with each other, especially after the outbreak of the pandemic COVID-19 when face-to-face communication increases the possibility of infection. Computer-mediated communication (CMC) is now an important mode of communication which, as a radical departure from the traditional communication process, changes the presentation of expressing oneself, the nature of nonverbal symbols, the construction of verbal codes and feedback patterns, and the development of closeness (Chen \& Wang, 2013).

There are several forms of computer-mediated communication - instant messaging, email and bulletin board systems (BBS), etc. Among these forms, instant messaging, with its unique characteristics in style, whether it is on mobile phone or other devices, is the activity the absolute majority of all internet users do on their devices. Since CMC is different from what happens in face-to-face communication in natural environment, the style of the language used in CMC should also be different.

There are many social conventions that people observe when they communicate with each other in face-to-face communication, of which politeness is an important one. In order to achieve successful communication, being aware of politeness is required. But do people observe principles of politeness similarly in CMC? What kinds of strategies do they employ when they make requests? How do people respond to the requests made through CMC? Do they use language or strategies differently, compared with face-to-face communication?

This study aims to investigate requests and responses made in CMC by Chinese college students from the perspective of politeness. On the basis of the previous theories and approaches to politeness, this study will focus on how Chinese college students use politeness strategies when making requests and responses and discuss the applicability of discursive approach in examining politeness in CMC.

\section{LITERATURE REVIEW}




\section{A. Computer-mediated Communication (CMC)}

According to Yus (2011), CMC involves a lot of exchanges of message of a written, audio-visual and multimodal quality, and most of them with an oral connotation. Though the texts in CMC are typed, they are often seen as a mixture of written text and speech, because they appear to be stable and rigid like written texts on the one hand, and spontaneous and ephemeral on the other (Yus, 2011). This has precisely captured some characteristics of CMC, which facilitates human communication and interaction. On the internet, written texts still take up the majority of the all varieties of messages. In most cases, pictures, audios and videos are supplementary to the information conveyed through texts. Another kind of form frequently used by young people to convey information or to express their feelings when communicating on the internet is stickers or emojis.

Studies on CMC started very early since the internet began to be used for communicative purposes. Hiltz and Turoff (1978) are two of the earliest researchers who touched upon the field of CMC research. Baron (1984) was one of the first scholars who documented ways in which CMC influences the way ideas are expressed. Murray (1988) compares and contrasts the characteristics of CMC with normal written and oral communication and focuses on the salient features of CMC: the organization of conversation, surface discourse features and the choice of medium and medium-switching.

Herring (1996) edited a book which presents papers concerning CMC from linguistic, social and cultural perspectives. Collot and Belmore (1996) view CMC as a new variety of English and analyze the lexical and grammatical features of a corpus which includes a large number of computer-mediated messages on a BBS in Canada. Yates (1996) compares his corpus with computerized corpora of spoken and written English, showing that in terms of vocabulary use, CMC is more like written language, but in the use of personal pronouns, it is similar to spoken language and CMC makes greater use of modal auxiliaries than speech and writing. Werry (1996) analyzes Internet Relay Chat (IRC) from the perspectives of addressivity, abbreviation, paralinguistic and prosodic cues, actions and gestures, pointing out its distinctive and interactional features. Ma (1996) investigates the effects that synchronous relay chat exchanges could have on cross-cultural communication between East Asian and North American university students. With previous comparisons among CMC, written communication and oral interaction, Baron (1998) further points out that email, as a form of $\mathrm{CMC}$, is a creole, a hybrid form of communication between spoken and written discourse.

Crystal is one of the leading scholars on CMC. His greatest contribution to this field is the publication of the book Language and the Internet in 2001. He believes that the internet is a technological and social revolution. Crystal (2001) thinks that language is central to the revolution of technology and society and he explores the role of language on the internet and the effect of the internet on language. Two chapters of the book are devoted to the explanation of "Netspeak", looking at features common to most internet communications. He regards "Netspeak" as the "third medium", different from speech and writing and a motivation for the expansion and enrichment of language. In his book, he describes the linguistic features of email, chatgroups, virtual worlds and the web in detail.

In China, online communication also attracted scholars' attention. The Dictionary of Chinese Netspeak edited by Yu (2001a) is one of the early studies of CMC. In his book General Introduction to Netspeak, Yu (2001b) investigates the stylistic characteristics, general qualities and lexical features of Chinese netspeak respectively. In the book, he compares the netspeak in mainland China and the netspeak in Taiwan, Hong Kong and Macau and also makes a comparison between the netspeak and the languages of traditional media. In addition, he analyzes people's attitudes toward netspeak and proposes some ideas on how to standardize and evaluate the Chinese netspeak. Dong and Liu (2001) employs stylistic theories to analyze the features of webchat English on the graphological, lexical, syntactic levels and investigates the reasons of the occurrence of such features by adopting the theories of register.

As CMC continues to develop, more and more researchers are turning their eyes on the language used in CMC due to its different characteristics. Scholars from various areas of study - pragmatics, stylistics, discourse analysis, etc. - can investigate the language used in $\mathrm{CMC}$ from diverse perspectives. The present paper mainly studies the language in CMC from the perspective of pragmatics, with the focus of how politeness strategies are used when making requests and responses in CMC.

\section{B. Politeness}

In face-to-face communication, language users always try to establish and maintain harmony with interlocutors in order to make the communication go smoothly as they wish. It is assumed that in CMC, people will do the same, though not many paralinguistic and extralinguistic cues can be provided and immediate responses are not always available. To build harmonious relationships, language users will need to employ linguistic strategies used in other modes of communication or use new strategies developed by themselves in CMC.

To achieve harmony in communication, politeness is an important factor. In pragmatics, politeness is an essential topic and there are a lot of definitions of politeness. Mills (2003:6) defines "politeness" as "the expression of the speakers' intention to mitigate face threats carried by certain face threatening acts toward another". In this definition, the notion of "face" is derived from Goffman's (1955) article, which is defined as "the positive social value a person effectively claims for himself" (Goffman, 1955:213), namely, a person's feeling of his or her own worth and image.

One of the most influential theories about politeness was Brown and Levinson's $(1978,1987)$ theory. They proposed the concept of face as the explanatory framework for politeness phenomena based on Goffman's (1955) notion of face. 
Brown and Levinson think that the concern for "face" is a universal phenomenon. According to their theory, face can be divided into two categories: positive face and negative face. Positive face refers to "the want of every "competent adult members' that his actions be unimpeded by others", whereas negative face is "the want of every member that his wants be desirable to at least some others" (Brown \& Levinson, 1987:67). In other words, positive face means people's need to make themselves accepted and appreciated by others and the desire to make sure that there is certain common ground between them and the social group. Negative face, on the other hand, refers to the desire to feel free and independent and not imposed upon.

They also believe that in most situations, our face is put at risk. Therefore, redressive language is used to compensate the threat to the face in the face-threatening acts (FTA) that are supposedly omnipresent. The use of redressive language is considered as an illustration of politeness. They summarized five politeness strategies to remedy the possible damage to other people's face: 1) do not do the FTA, 2) do it off record, 3) do it baldly on record, 4) adopt negative politeness, and 5) adopt positive politeness. As Brown \& Levinson (1987) pointed out, positive politeness is oriented towards a person's positive face by "treating the other as a member of an in-group, a friend, or a person whose wants and personality traits are known and liked”. By contrast, negative politeness is oriented to one's negative face by recognizing and showing respect for the other's freedom of action. Some speech acts are regarded as positive politeness strategies, such as praising, making a joke, seeking agreement, claiming reflexivity of goals, claiming reciprocity, and expressing sympathy, understanding and cooperation (Brown \& Levinson, 1987), whereas some other acts are viewed as negative politeness strategies, for example, showing deference, apologizing, or employing hedges or mitigating devices to lessen the effect of imposition. In summary, politeness is regarded as a form of strategic behavior in which the speaker engages, carefully considering and measuring the possible threat to the hearer, the extent of closeness with the hearer, the power relationship between them, and modifying the utterance according to these considerations. This view is similar to Grundy's (1995) idea, in which linguistic politeness is viewed as the function of language to imply the most appropriate relationship between the speaker and the addressee.

However, the above-mentioned studies are mainly concerned with face-to-face oral communication. Compared with spoken language, research on the language used in written form concerning politeness phenomena has been relatively rare. Studies on the politeness in CMC, the so-called "third medium", is even less. Myers (1989) argues that Brown and Levinson's (1978) framework of politeness can be extended to written texts. When analyzing scientific articles, Myers (1989) found that the use of "we" as a positive politeness strategy to indicate the discipline as a whole can achieve solidarity while personal attribution can be used as a hedge on one's claims. Hiemstra's (1982) study of politeness strategies in teleconferencing suggests that concerns for face was strongly evident in the language of conference although there was a shift to negative politeness and "bold on record" in CMC. These studies give support to Brown and Levinson's theory; however, their theory was also criticized by some scholars.

\section{Discursive Approach}

Although Brown and Levinson's theory is widely applicable, some weaknesses in their theory have been criticized. Among many critics, discursive approach serves both as a critique and as an alternative approach to the analysis of politeness.

For many scholars who study discursive politeness theories, Brown and Levinson's conception of how "politeness" should be defined is far from enough to fully describe the complexity of the term (e.g., Eelen, 2001; Watts, 2003). More importantly, politeness can be seen as including a much greater range of behaviors, instead of only looking into the strategic use of politeness which aims to avoid face-threat (Mills, 2003).

Brown and Levinson's approach is also weak because it ignores the importance of the hearer, and the hearer's perspective, in determining what constitutes politeness, and it also fails to take into consideration the social and discursive context in which utterances are made and politeness is negotiated (Watts, 2003). A discursive approach attaches importance to the notion that meaning can be dynamically constructed by "multiple participants over the course of longer stretches of discourse" (Mills, 2003; 2011).

Further, discursive approaches to the analysis of politeness find that Brown and Levinson's reliance on Speech Act Theory is problematic, as it involves a model of communication in which the speaker is the center and sentence is the focus, which forces them to presume that elements in a conversation are single-functioned and "are readily agreed upon by participants" (Van der Bom and Mills, 2015).

Many discursive theorists criticize Brown and Levinson for their excessive attention paid to the analyst's perception of what politeness means, rather than on how individual speakers and hearers understand the term in authentic interaction (e.g., Eelen, 2001; Clark, 2011; Watts, 2003; Grainger et al., 2015). According to Van der Bom and Mills (2015), there is a distinction between first order politeness (politeness1) and second order politeness (politeness2) made by discursive politeness theorists. Politeness 1 emphasizes "participants' judgements of what constitutes politeness in interaction", politeness 2 includes the more theoretical conception of what constitutes politeness (see Watts et al., 1992; Eelen, 2001). Discursive approaches have forced theorists to critically evaluate the role of politeness and impoliteness and the origin of politeness as a system and ideology from the social perspective (Agha 2006).

According to Van der Bom and Mills (2015), in discursive approaches, the interaction between participants is taken into account; longer stretches of discourse are chosen for analysis, and the perceptions of the individuals involved are emphasized in regard to what they judge as polite and impolite, therefore discursive approaches are considered as a 
more localized and interactive way of analysis and they focus more on the context (Van der Bom and Mills, 2015). With regard to politeness, discursive approaches are more concerned with "ideologies of politeness and impoliteness" (Van der Bom and Mills, 2015). Thus, a discursive approach focuses on judgement and interpretation that are more contextualized and localized and more socially-focused (Van der Bom and Mills, 2015).

Van der Bom and Mills (2015) provided a very detailed example analysis to explain the different aspects that a discursive approach might comprise, and thus how this approach can be applied when investigating politeness. They first discussed the methods of collecting data and the type of data they chose for their study before they try to get participants' evaluations of the selected extract of communication. Then they analyzed the participants' judgements and drew some conclusions concerning the way how politeness works in the interaction. What should be paid special attention to is that the texts for analysis consist of the interaction which is initially recorded and the recordings of how the participants evaluate and judge about their initial interaction. Finally, they addressed how the interplay of the original conversation, together with the participants' evaluations and judgements of politeness in the interaction, and the analyst's view, could possibly lead to "a second-order understanding of politeness and impoliteness" (Van der Bom and Mills, 2015). In their final section, ideologies of politeness and impoliteness are their particular focus.

\section{Request and Response}

There are many different ways to define request. As a speech act, a request is seen as a pre-event act which expresses the speaker's expectation of the hearer in relation to some expected action required by the circumstances (Blum-Kulka et al., 1989; Bargiela-Chiappini \& Harris, 1996). The main purpose of a request is to ask the hearer to "provide information or perform an action" for the speaker or the group that the speaker and hearer belong to (Ho, 2018).

According to Ho (2018), previous studies investigating requests in CMC context have paid so much attention to the interaction between EFL learners and faculty, which are especially concerned with the use of pragmatic politeness in students' requests through emails sent to their faculty. These studies, according to Ho's (2018) classification, mainly discuss (a) the pragmatic failure illustrated by the students (e.g., Chejnova, 2014; Economidou-Kogetsidis, 2011); (b) the way students' use of politeness could influence faculty's perception of the students' personality (Economidou-Kogetsidis, 2016) and of the (im)politeness and (in)appropriateness of the emails (Savic, 2018); and (c) the type and quantity of resources students used when they wrote polite emails, reinforcing the necessity to pedagogically intervene in the acquisition of pragmatic politeness (Biesenbach-Lucas, 2007).

A usual daily activity as it may seem, making a request should be taken seriously. Ho (2018) summarizes the reasons why making a request in the workplace is so important, which also hold true for college students' communication. Specifically, the reasons are: (1) it is a high stake act because an appropriate request is more likely to be responded to satisfying answers so that the requestor's task would then be completed; (2) the act of request could pose challenges and sometimes damages to the rapport between the two parties (Spencer-Oatey, 2008); and (3) a well-constructed request could not only fulfill the requestor's needs by receiving the information or getting an action done but also bring extra benefits to the requestor, such as constructing "desirable personal identities" and establishing "stronger rapport with the requestee" (Ho, 2010, 2014). It is therefore important for college students to be knowledgeable about the linguistic resources that they can apply in making requests that are persuasive enough to achieve "request compliance" - the requestor's needs are satisfied, and cause no harm to the harmony between the requestor and the requestee (Ho, 2018).

After making a request, the requestor may expect a response from the requestee. It is equally important for the requestee to make responses in a polite way, especially when he or she is unable or unwilling to do what the requestor wants him or her to do. Therefore, as a continuing step, both making requests and giving responses need to be investigated from the perspective of politeness in order to better understand what kind of strategies are used to achieve effective communication.

\section{METhODOLOGY}

\section{A. Research Questions}

The main purpose of this paper is to investigate requests and responses made in CMC by Chinese college students from the perspective of politeness. Two specific research questions are proposed:

1. How do Chinese college students use politeness strategies when making requests and responses in CMC?

2. Does discursive approach apply well in analyzing the politeness in CMC? How does it differ from face-to-face communication?

Based on the discursive approach, the first question will be answered by selecting some extracts of chat history on WeChat, a popular instant-messaging application in China, presenting the extracts to the interlocutors and asking them to judge the conversations from the perspective of politeness. Especially when they feel difficulties or encounter face-threatening acts in the conversation, politeness strategies can be elicited.

For question 2, this study itself can be a demonstration of using discursive approach in analyzing politeness in CMC. By comparing with previous studies using this approach in analyzing face-to-face conversation, the differences could be found.

B. Data Collection 
As is shown in Table 1, the data used for this study consist of the chat history between the author (as "I" for convenience) and four classmates on WeChat from the beginning of the year 2018 till August $1^{\text {st }}, 2018$. Both the author and the four interlocutors are in their 20s. The pseudonyms for the four interlocutors are A, B, C and D. There are three males (including the author himself) and two females as the interlocutors involved in this study. All the participants are Chinese native-speakers, and they are all proficient in using English as a foreign language. The participants also share similar educational background, because they are classmates in the same university. Though all of them are classmates, they differ in their closeness with the author. To know about the closeness, the author asked the interlocutors to give a score from 1 to 7 , from the least close to the most.

There are 895 messages in total, including texts, stickers, emojis, pictures, documents, voice messages, records of transfers and red packets. The data collected have been coded by 2 researchers according to the definition of requests. After coding, the two sets of results were statistically examined, which shows a high inter-rater reliability.

TABLE I.

BASIC INFORMATION ABOUT THE PARTICIPANTS AND CHAT HISTORY

\begin{tabular}{|l|l|l|l|l|}
\hline \multicolumn{2}{|c|}{ BASIC INFORMATION ABOUT THE PARTICIPANTS AND CHAT HISTORY } \\
\hline Pairs of interlocutors & $\begin{array}{l}\text { Genders of the } \\
\text { interlocutor }\end{array}$ & $\begin{array}{l}\text { Score } \\
\text { closeness }\end{array}$ & $\begin{array}{l}\text { Total number of } \\
\text { messages }\end{array}$ & $\begin{array}{l}\text { Number of messages } \\
\text { indicating requests }\end{array}$ \\
\hline I \& A & Female & 6 & 330 & 81 \\
\hline I \& B & Female & 4 & 128 & 40 \\
\hline I \& C & Male & 6 & 259 & 35 \\
\hline I \& D & Male & 5 & 178 & 28 \\
\hline
\end{tabular}

Following Van der Bom and Mills' (2015) steps, apart from the chat history, the four interlocutors are asked to discuss which parts of the extract of conversations might be of interest for politeness analysis. The focus is on what the participants of these conversations considered to be moments of interactional difficulty or awkwardness, as these might be considered as the moments when politeness or impoliteness is likely to be employed. The discussion was conducted on WeChat by combing and forwarding the selected chat history to the participants and asking them to make judgements.

\section{Procedures for Data Analysis}

According to Van der Bom and Mills (2015), some extracts of the conversations were chosen because they seemed to constitute difficult moments in the interactions in which potential face-threatening acts are evident. Instead of starting the analysis with a focus on linguistic elements such as "sorry" or the use of "would you mind", which can be separately seen as indicators of politeness, the focus of the present study is the moments in the interaction which appear to be difficult or having interactional problem from the participants' perspective. That moment of difficulty was then tracked through, attempting to isolate the elements or strategies that the interlocutors in the interaction employed to avoid or resolve the difficulty. When difficult situations arise in interactions, politeness seems to become a key element which is drawn upon by the participants to make their communication go smoothly.

\section{FINDINGS AND DISCUSSIONS}

The following figure is a screenshot of the chat history between the author ("I") and interlocutor B.

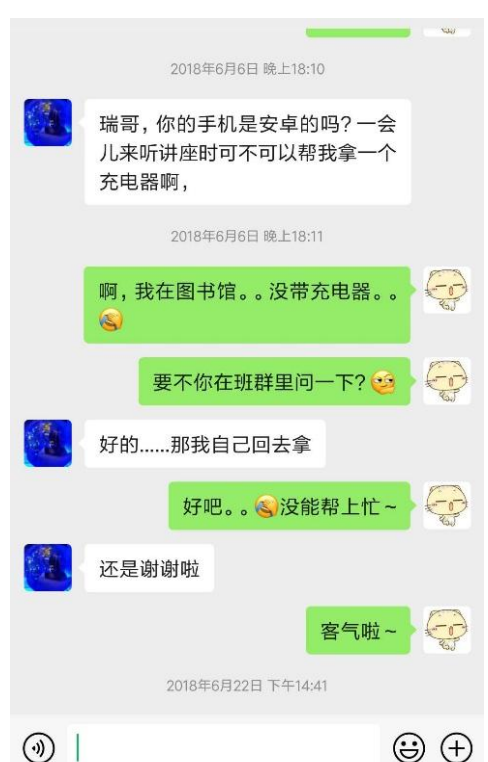

Figure 1. A screenshot of the chat history between "I" and B on WeChat. 
The following is the transcription and translation of the chat history in Fig.1:

[1] B：瑞哥, 你的手机是安卓的吗? 一会儿来听讲座时可不可以帮我拿一个充电器啊,

Bro Rey, is your mobile phone with Android system? Could you help me to bring a charger when you come to the lecture a moment later,

[2] I: 啊, 我在图书馆。没带充电器。。

Ah, I am in the library... no charger with me... [Facepalm]

[3] I: 要不你在班群里问一下?

How about ask it in the WeChat group of our class? [Smart]

[4] B：好的......那我自己回去拿

Okay......then I myself will go back to bring it

[5] I: 好吧。。 没能帮上忙

Okay... [Facepalm] I cannot offer you help

[6] B: 还是谢谢啦

Anyway, thanks

[7] I: 客气啦

You're welcome

After having this extract selected, this part of chat history was combined and forwarded to B and she is also asked to read the extract and give an evaluation of the situation. B commented:

I think we both were polite in that conversation. When I make the request, I used strategies to be polite and when you respond to me, you are also polite even though you didn't actually help me. The difficult moment in the situation might be that you tell me that you cannot help me. I think you must have experienced inner conflict when you reply me because you are always so helpful but this time you cannot help me.

She thought that she did not use any face-threatening acts. On the contrary, she used strategies to achieve politeness:

When I ask you to borrow the mobile phone charger, I didn't directly ask you about the charger in the first place, instead, I asked you whether your mobile phone is Android. The fact is, I knew your phone is Android before I ask you. So, this question is not simply a confirmation question but a device to achieve politeness, because I feel that directly asking about the charger is not so appropriate. By the way, the way I address you is also an illustration of politeness. I think it is rude to suddenly send you a message "Can you help me to bring a mobile phone charger?" without addressing you. I think using addressing term is more polite than not using it no matter how close the relationship is. And I said "thanks" to you although you cannot offer me help. That's another sign of politeness.

From B's point of view, the use of proper addressing terms, indirect speech and expressing gratitude are the strategies of politeness. When asking B about the author's politeness strategies, she said:

When you reply to my request, you said "Ah...", which seems to be hesitating. Then you tell me that you are in the library, which is also an indirect speech, suggesting that you cannot help me at the moment. Then you tell me that you didn't take a charger with you, which is the harsh reality and the real reason why you cannot help me this time. You didn't directly say "No" or "I can't help you" and you didn't tell me the harsh reason first. These are the signs of politeness. After telling me the reason, you added a possible solution for me by suggesting me to ask it in the class group, indicating that you still want to offer me some help. And I can read from your saying "Okay... I cannot offer you help " that you feel somehow guilty for not able to fulfill my request. Your use of Facepalm emoji indicates that you want to mitigate the situation, making it less embarrassing.

But for the author, the difficult moment is different. When the author suggested B to ask the question of whether anyone has taken a charger with him/herself in the class WeChat group, B's response "Okay......then I myself will go back to bring it" seems to be a little bit face-threatening. B did not directly respond to the author's suggestion and the utterance she made seems to suggest that B is helpless. The author even thought maybe his suggestion annoyed B. From the analysis of both the author and the interlocutor B, it can be seen that the requestor and the requestee may interpret the same language quite differently.

The cases with other interlocutors show similar results. In terms of politeness strategies, both positive politeness and negative politeness are used. For example, positive politeness includes using appropriate addressing terms that can indicate closeness, offering suggestions, and attending to the hearer's interests, needs, wants, etc. and negative politeness involves using indirect speech, hedges or questions, apologizing, etc.

After employing the discursive approach to the analysis of politeness in CMC, the results show similar patterns with previous studies and the politeness strategies used by the interlocutors can be associated with what Brown and Levinson's (1987) theory suggests. These indicate that discursive approach can be applied in analyzing politeness in $\mathrm{CMC}$ well. However, it is, to some extent, different from face-to-face communication. Compared with Van der Bom and 
Mills' (2015) study, using discursive approach in analyzing the politeness in CMC has several differences: 1) the extract of conversation is shorter, since in CMC, the communication is basically achieved through typing messages. The messages are generally shorter than the language face-to-face communication could produce. 2) there are many non-linguistic ways to achieve politeness in CMC, such as sending stickers or emojis, red packets and pictures, etc. 3) in $\mathrm{CMC}$, due to the invisibility of the interlocutor, misunderstanding may occur because it is hard to know the tones, moods, feelings and emotions behind the messages. 4) in CMC, collecting the conversation as research data is comparatively easier. The messages on instant messaging applications like WeChat can be easily saved and reposted. While in face-to-face communication, the conversation has to be recorded and replayed to the interlocutors.

\section{CONCLUSION}

This study employed discursive approach to the analysis of politeness in making requests and responses in CMC. By analyzing the data of the author and four interlocutors extracted from the chat history on WeChat, this study found that various strategies are used in order to achieve politeness in CMC, such as using appropriate addressing terms that can indicate closeness, offering suggestions, attending to the hearer's interests, using indirect speech, hedges or questions, etc. This study also found that discursive approach can be applied in analyzing politeness in CMC well.

However, this study also has a lot of limitations. First, to draw more general conclusions, the data needs to be expanded instead of having only four interlocutors. Second, the result may be influenced by the subjectivity of the author since the chat history adopted in this study is between his classmates and himself. For future studies, there should be more interlocutors involved and the data should exclude the author in order to avoid subjectivity.

\section{REFERENCES}

[1] Agha, Asif. (2006). Language and social relations. Cambridge: Cambridge University Press.

[2] Bargiela-Chiappini, F. \& Harris Sandra. (1996). Requests and status in business correspondence. Journal of Pragmatics, 28, 635-662.

[3] Baron, N. S. (1984). Computer mediated communication as a force in language change. Visible Language, 2, 118-141.

[4] Baron, N. S. (1998). Letters by phone or speech by other means: the linguistics of email. Language and Communication, 18, $133-170$.

[5] Biesenbach-Lucas, Sigrun. (2007). Students writing e-mails to faculty: an examination of e-politeness among native and non-native speakers of English. Language Learning Technology, 11, 59-81.

[6] Blum-Kulka, S., Juliane House \& Gabriele Kasper. (1989). Cross-cultural Pragmatics: Requests and Apologies. Norwood, NJ: Ablex Publishing Corporation.

[7] Brown, P. \& Levinson, S. C. (1978). Universals in Language Usage: Politeness Phenomena. In Goody, E. N., Questions and Politeness: Strategies in Social Interaction. Cambridge: Cambridge University Press. 56-311.

[8] Brown, P. and Levinson, S. C. (1987). Politeness: Some Universals in Language Usage. Cambridge: Cambridge University Press.

[9] Chejnova, P. (2014). Expressing politeness in the institutional e-mail communications of university students in the Czech Republic. Journal of Pragmatics, 60, 175-192.

[10] Chen, H., \& Wang, M. (2013). Gender Discourse Patterns of Taiwan College Students in Social-Based Computer-Mediated Chat Rooms. Chinese Journal of Applied Linguistics (Quarterly), 36, 368-382.

[11] China Internet Network Information Center. (2018). The $41^{\text {st }}$ China Statistical Report on Internet Development. https://www.cnnic.net.cn/hlwfzyj/hlwxzbg/hlwtjbg/201803/P020180305409870339136.pdf (accessed 20/8/2018).

[12] Clark, Jodie. (2011). "No, like proper north": Re-drawing boundaries in an emergent community of practice. In Linguistic Politeness Research Group (Ed.), Discursive approaches to politeness. Berlin \& New York: Mouton de Gruyter, 109-132.

[13] Collot, M., \& Belmore, N. (1996). Electronic language: a new variety of English. In Susan C. Herring (Ed.), Computer-Mediated Communication: Linguistic, Social and Cross-cultural Perspectives. Amsterdam: John Benjamins, 13-28.

[14] Crystal, D. (2001). Language and the Internet. UK: Cambridge University Press.

[15] Dong, Q. M. \& Y. M. Liu. (2001). Stylistic features of webchat English. Foreign Language Teaching and Research (bimonthly), $1,42-47$.

[16] Economidou-Kogetsidis, Maria. (2011). "Please answer me as soon as possible": pragmatic failure in non-native speakers' e-mail requests to faculty. Journal of Pragmatics, 43, 3193-3215.

[17] Economidou-Kogetsidis, Maria. (2016). Variation in evaluations of the (im)politeness of emails from L2 learners and perceptions of the personality of their senders. Journal of Pragmatics, 106, 1-19.

[18] Eelen, Gino. (2001). A critique of politeness theories. Manchester: St. Jerome.

[19] Goffman, Erving. (1955). On Face-Work: An Analysis of Ritual Elements in Social Interaction. Psychiatry, 18, $213-231$.

[20] Grainger, K., Zainab Kerkam, Fathia Mansor \& Sara Mills. (2015). Offering and hospitality in Arabic and English. Journal of Politeness Research, 11(1), 41-70.

[21] Grundy, Peter. (1995). Doing Pragmatics. New York: St. Martin's Press Inc.

[22] Herring, S. C. (Ed.). (1996). Computer-Mediated Communication: Linguistic, Social and Cross-cultural Perspectives. Amsterdam: John Benjamins.

[23] Hiltz, S. R., \& Turoff, M. (1978). The Network Nation: Human Communication Via Computer. Heading, MA: Addison Weslay.

[24] Ho, Victor. (2010). Constructing identities through request e-mail discourse. Journal of Pragmatics, 42 (8), $2253-2261$.

[25] Ho, Victor. (2014). Managing rapport through evaluation in grounder e a qualitative study. Journal of Pragmatics, 61, 63-77.

[26] Ho, Victor. (2018). Using metadiscourse in making persuasive attempts through workplace request emails. Journal of Pragmatics, 134, 70-81. 
[27] Ma, R. (1996). Computer-mediated conversations as a new dimension of inter-cultural communication between East Asian and North American college students. In Herring, S. C. (Ed.), Computer-Mediated Communication: Linguistic, Social and Cross-cultural Perspectives. Amsterdam: John Benjamins, 173-186.

[28] Mills, Sara. (2003). Gender and politeness. Cambridge: Cambridge University Press.

[29] Mills, Sara. (2011). Discursive approaches to politeness and impoliteness. In Linguistic Politeness Research Group (ed.), Discursive approaches to politeness. Berlin \& New York: Mouton de Gruyter. 19-56.

[30] Murray, D. E. (1988). Computer-mediated communication: implications for ESP. English for Special Purpose, 7, 3-18.

[31] Myers, Greg. (1989). The Pragmatics of Politeness in Scientific Articles. Applied Linguistics, 10, 1-35.

[32] Savic, Milica. (2018). Lecturer perceptions of im/politeness and in/appropriateness in student e-mail requests: a Norwegian perspective. Journal of Pragmatics, 124, 52-72.

[33] Spencer-Oatey, H. (2008). Face, (im)politeness and rapport. In Spencer-Oatey, H. (Ed.), Culturally Speaking: Culture, Communication and Politeness Theory ( $2^{\text {nd }}$ ed). London; New York: Continuum, 11-47.

[34] Van der Bom, Isabelle and Mills, Sara. (2015). A discursive approach to the analysis of politeness data. Journal of Politeness Research, 11 (2), 179-206.

[35] Watts, Richard J., Sachiko Ide \& Konrad Ehlich. (1992). Introduction. In Richard J. Watts, Sachiko Ide \& Konrad Ehlich (eds.), Politeness in language: Studies in its history, theory and practice. Berlin: Mouton de Gruyter. 1-17.

[36] Watts, Richard J. (2003). Politeness. Cambridge: Cambridge University Press.

[37] Werry, C. C. (1996). Linguistic and Interactional Features of Internet Relay Chat. In Computer-Mediated Communication: Linguistic, Social and Cross-cultural Perspectives (pp. 47-63). Amsterdam: Benjamins.

[38] Yates, S. (1996). Oral and written linguistic aspects of computer conferencing: a Corpus Based Study. In Herring, S. C. (Ed.), Computer-Mediated Communication: Linguistic, Social and Cross-cultural Perspectives. Amsterdam: John Benjamins, 29-46.

[39] Yus, F. (2011). Cyberpragmatics: Internet-Mediated Communication in Context. Amsterdam: John Benjamins.

[40] Yu, G. Y. (2001a). Zhongguo Wangluo Yuyan Cidian [The Dictionary of Chinese Netspeak]. Beijing: Economic Press China.

[41] Yu, G. Y. (2001b). Wangluo Yuyan Gaishuo [General Introduction to Netspeak]. Beijing: Economic Press China.

Zhongrui Wang was born in Anqing, China in December, 1992. He received his master's degree in English Linguistics and Applied Linguistics from Beijing Foreign Studies University, China in 2019.

$\mathrm{He}$ is currently a teacher in the College of Foreign Languages, Guangdong University of Science and Technology, Dongguan, China. His research interests include applied linguistics, intercultural communication and language education. 